\title{
Catalyzed Signal Amplification for Cyclin D1 Detection in Mantle Cell Lymphoma
}

Carlos Barranco, M.D., José L. Mate, M.D., Aurelio Ariza, M.D., Teresa Baró, B.Sc., Esther Díaz, M.D., Assumpta Munné, M.D., Sergi Serrano, M.D.

Department of Pathology (CB, TB, ED, AM, SS), Hospital del Mar, and Department of Pathology (JLM, AA), Hospital Germans Trias i Pujol, Autonomous University of Barcelona, Barcelona, Spain

Mantle cell lymphoma is characterized by a $t(11$; 14)(q13;q32) translocation resulting in cyclin D1 protein overexpression. Immunohistochemical detection of the latter, therefore, is a useful marker for the diagnosis of mantle cell lymphoma. Nevertheless, interpretation of results is often hampered by the weak immunoreactivity obtained with routine detection techniques. This problem can be overcome by resorting to highly sensitive catalyzed signal amplification methods based on peroxidasecatalyzed deposition of a biotinylated phenolic compound. The present study compares the results obtained with catalyzed signal amplification, labeled streptavidin biotin, and dextran polymeric conjugate (EnVision+) techniques in cyclin D1 demonstration in mantle cell lymphoma. The study was performed on formalin-fixed, paraffinembedded archival tissue from 20 mantle cell lymphoma cases. Ten cases of small lymphocytic lymphoma and 10 instances of follicular center cell lymphoma were used as controls. Antigen retrieval was done by autoclaving under controlled pressure ( 2 bar) and temperature $\left(120^{\circ} \mathrm{C}\right)$ conditions. The best results were obtained after 1 minute of exposure with catalyzed signal amplification and after 6 minutes with other detection systems. Regarding cyclin D1 expression in mantle cell lymphoma cases, $17(85 \%)$ were weakly positive and $3(15 \%)$, moderately positive with labeled streptavidin biotin, whereas $15(75 \%)$ were weakly positive and 5 (25\%) moderately positive with EnVision + . In contrast, all 20 mantle cell lymphoma cases were strongly cyclin D1 positive with catalyzed signal am-

Copyright () 2003 by The United States and Canadian Academy of Pathology, Inc.

VOL. 16, NO. 2, P. 161, 2003 Printed in the U.S.A.

Date of acceptance: November 8, 2002.

Supported by DURSI Grant 2001SGR00400 from the Generalitat de Catalunya.

Address reprint requests to: Sergi Serrano, M.D., Department of Pathology, Hospital del Mar, Passeig Maritim 25-29, 08003 Barcelona, Spain; e-mail: sserrano@imas.imim.es.

DOI: 10.1097/01.MP.0000051585.74803.09 plification. No evidence of cyclin D1 immunostaining was obtained in any of the small lymphocytic lymphoma and follicular center cell lymphoma instances with any of the three methods used. In conclusion, catalyzed signal amplification methods provide a very useful tool for cyclin D1 demonstration in cases in which other immunohistochemical techniques yield inconclusive results.

KEY WORDS: Catalyzed signal amplification, Cyclin D1, Immunohistochemistry, Mantle cell lymphoma. Mod Pathol 2003;16(2):161-165

Mantle cell lymphoma, a malignant proliferation of small or medium-sized B lymphocytes that are the neoplastic counterpart of normal lymphoid follicle mantle cells, adopts a variety of growth patterns. This neoplasm is associated with a median survival of 3-5 years and lack of cure in the vast majority of patients. In fact, the 5-year overall survival of mantle cell lymphoma patients $(30 \%)$ is among the worst for the various lymphoma types (1-7). Distinguishing this more aggressive type of B-cell lymphoma from others (marginal zone, small lymphocytic, and follicular lymphomas) can be very difficult.

The most useful mantle cell lymphoma marker is cyclin D1, a cell cycle regulator that stimulates transition from G1 phase to $S$ phase by cooperating with cdk4-6 in Rb phosphorylation and E2F release. Normally, lymphocytes do not express cyclin D1 or produce it in very low, immunohistochemically undetectable levels. In contrast, mantle cell lymphoma lymphocytes show immunohistochemically demonstrable cyclin D1 overexpression as a consequence of a $\mathrm{t}(11 ; 14)(\mathrm{q} 13 ; \mathrm{q} 32)$ translocation involving the $b c l-1$ region of chromosome 11 and the immunoglobulin heavy chain gene of chromosome $14(8-10)$. This translocation is shown by cytogenetics or Southern blotting techniques in $70-75 \%$ of mantle cell lymphoma cases and by fluorescence in situ hybridization (FISH) studies in virtually all mantle cell lymphoma cases (11). As for immuno- 
histochemistry, it detects cyclin D1 overexpression in virtually $100 \%$ of mantle cell lymphoma cases (8-10). Often, however, the immunoreaction signal provided by routine detection systems is of weak or moderate intensity. On the other hand, catalyzed signal amplification methods are extremely sensitive and very useful when antigen concentration is below the detection threshold of routine immunohistochemical procedures. Consequently, they are able to yield stronger intensities and significantly improve the results obtained with commercially available anti-cyclin D1 monoclonal antibodies (12, 13).

In this work we have compared the effectiveness of catalyzed signal amplification, labeled streptavidin biotin, and dextran polymeric conjugate (EnVision+) detection systems for cyclin D1 demonstration in mantle cell lymphoma. Additionally, to explore whether the increased sensitivity associated with these techniques affects specificity in any way, cases of small lymphocytic lymphoma and follicular center cell lymphoma were included in the study.

\section{MATERIAL AND METHODS}

Formalin-fixed, paraffin-embedded tissue from 20 mantle cell lymphoma, 10 small lymphocytic lymphoma, and 10 follicular center cell lymphoma cases was retrieved from the archives of the Departments of Pathology of Hospital del Mar and Hospital Germans Trias i Pujol, Barcelona, Spain. In each instance, the immunophenotype was characteristic of the respective lymphoma type. Specifically, mantle cell lymphoma cases were CD20+, CD5+, CD23-, and CD10-; small lymphocytic lymphoma cases were $\mathrm{CD} 79 \mathrm{a}+, \mathrm{CD} 5+, \mathrm{CD} 23+$, and $\mathrm{CD} 10-$; and follicular center cell lymphoma cases were $\mathrm{CD} 20+, \mathrm{CD} 10+, \mathrm{CD} 5-$, and $\mathrm{CD} 23-$.

Sections 3 to $4 \mu \mathrm{m}$ thick were deparaffinized in xylene and hydrated. Because autoclaving provides a very fine control of the pressure and temperature applied to samples, we resorted to this system as a source of heath for antigen retrieval. All samples were autoclaved in buffer citrate at $\mathrm{pH}$ 7.4, 2 bar pressure, and $120^{\circ} \mathrm{C}$ temperature. Incubation time was optimized for every detection system employed. Thus, catalyzed signal amplification yielded best results after just 1 minute of antigen retrieval, whereas the other two detection systems needed 6 minutes each to achieve maximally intense immunostaining against a clean background.

Anticyclin D1-GM (Novocastra, Newcastle, UK) was used as primary antibody. The three detection systems employed were as follows: labeled streptavidin biotin (DAKO, Glostrup, Denmark), EnVision $+(\mathrm{DAKO})$, and catalyzed signal amplification (DAKO).
Anti-cyclin D1-GM monoclonal antibody was used at a 1:50 dilution with the labeled streptavidin biotin and EnVision + detection systems and at a 1:500 dilution with the catalyzed signal amplification method. All immunostaining procedures were carried out with the aid of Autostainer (DAKO). Results were independently evaluated by three pathologists as follows: $(-)$ negative, $(+)$ weakly positive, $(++)$ moderately positive, and $(+++)$ strongly positive.

\section{RESULTS}

Regardless of the detection system employed, all mantle cell lymphoma cases showed nuclear positivity for cyclin D1. On the contrary, every small lymphocytic lymphoma and follicular center cell lymphoma case was cyclin D1 negative. As for the various detection systems used, catalyzed signal amplification was the most efficient in achieving a very strong signal intensity in the absence of significant background staining. Thus, all 20 mantle cell lymphoma cases included in the study were strongly positive for cyclin D1 when the catalyzed signal amplification method was used, whereas the intensity yielded by the labeled streptavidin biotin and EnVision + systems was only weak $(75 \%$ and $85 \%$ of mantle cell lymphoma cases, respectively) or moderate (25\% and $15 \%$, respectively; Fig. 1$)$. Table 1 summarizes these results.

\section{DISCUSSION}

As a small cell lymphoma, mantle cell lymphoma with a nodular pattern may mimic follicular center cell lymphoma, marginal zone lymphoma, and small lymphocytic lymphoma, but immunophenotypic differences usually allow distinction among these various entities. Nevertheless, when the immunophenotypic profile is atypical or tissue availability is suboptimal, reaching a diagnosis may be fraught with difficulties. This is particularly true in regard to the distinction between mantle cell lymphoma and small lymphocytic lymphoma, which share a substantial part of their phenotypic and cytologic features. Because mantle cell lymphoma aggressive behavior makes its discrimination from the remainder of small cell lymphomas of paramount importance, recourse to other diagnostic tools is mandatory. Very helpful in this setting is the demonstration of a $\mathrm{t}(11 ; 14)$ translocation leading to cyclin D1 overexpression in mantle cell lymphoma. Detection of this translocation is made possible by cytogenetic, FISH, Southern blot, or PCR studies, whereas overexpression of cyclin D1 can be assessed by more readily available immunohistochemical methods. Unfortunately, formalin fixation 

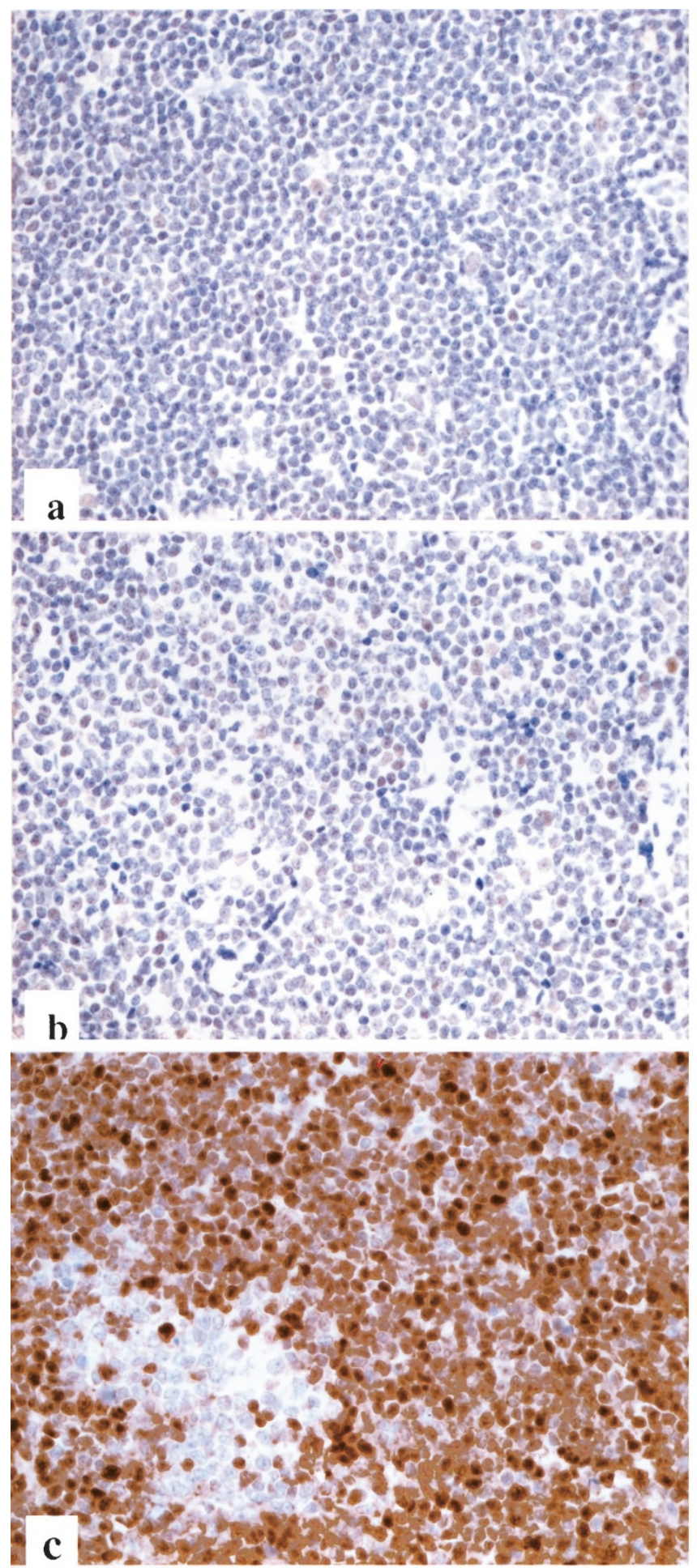
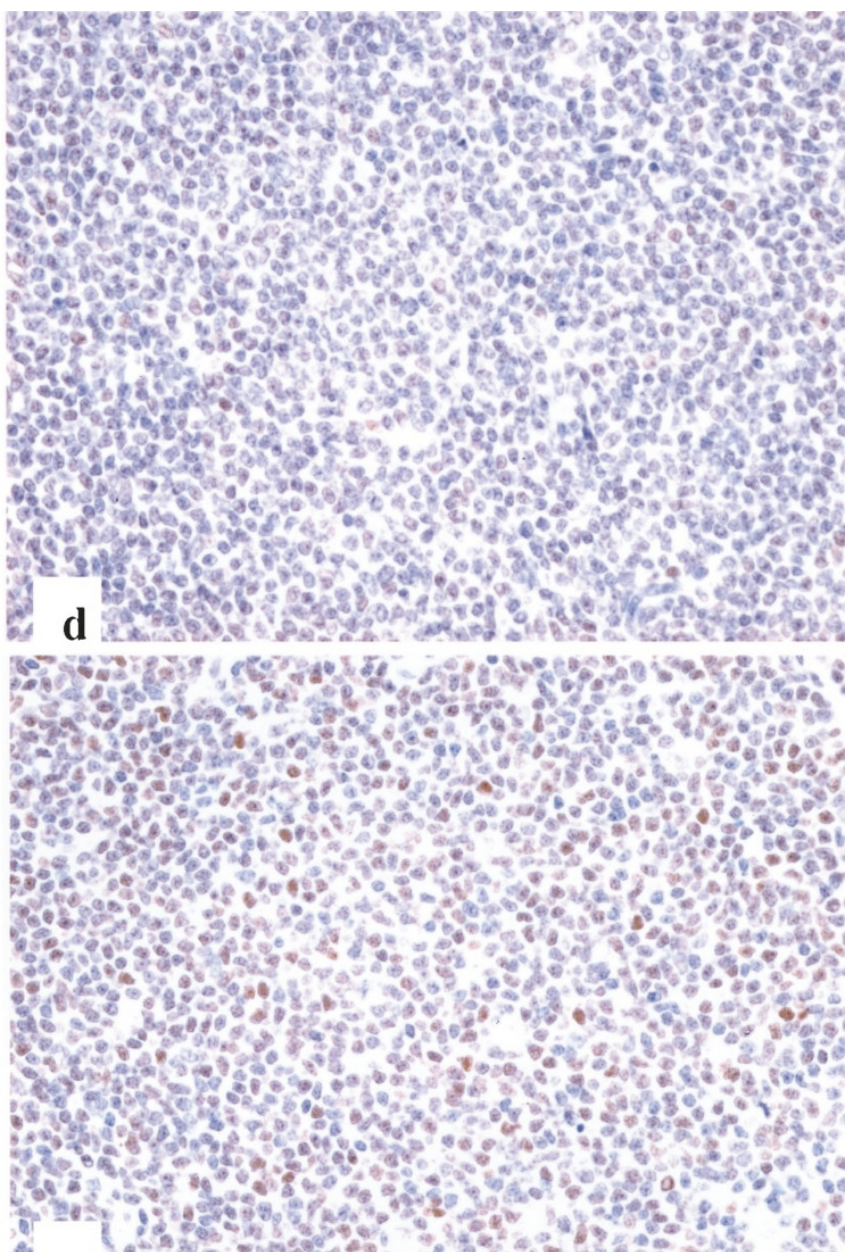

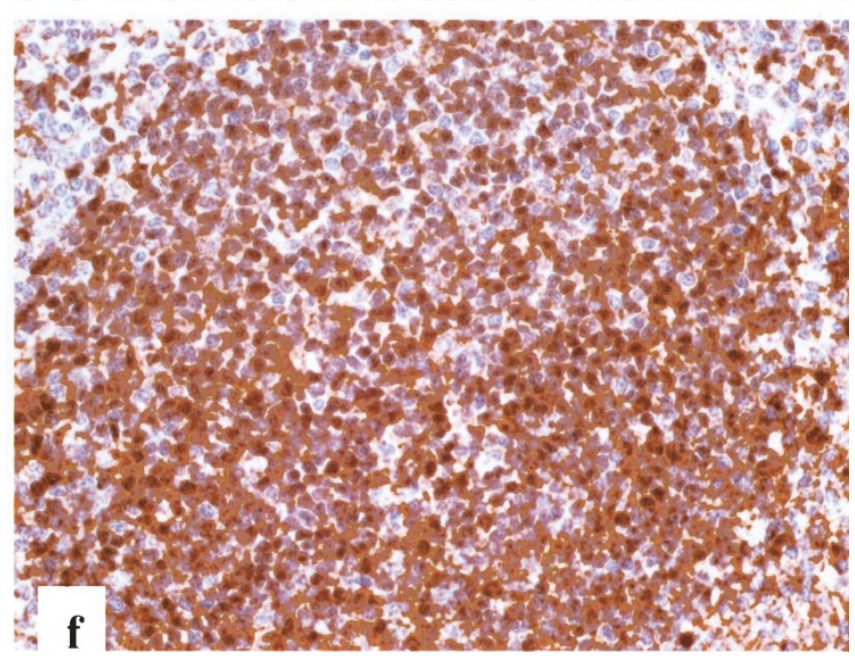

FIGURE 1. Cyclin D1 expression as demonstrated by labeled streptavidin biotin (weak, A), EnVision+ (weak, B), and catalyzed signal amplification (strong, C) in one mantle cell lymphoma case and by labeled streptavidin biotin (weak, D), EnVision+ (moderate, E), and catalyzed signal amplification (strong, F) in another mantle cell lymphoma case. A reactive germinal center surrounded by cyclin D1-positive tumor cells may be seen in C (cyclin D1, 400×).

and paraffin embedding of tissue greatly jeopardizes immunohistochemical demonstration of cyclin D1. This hurdle can be overcome by a variety of strategies based on improvement of antigen retrieval, employment of several antibodies, or use of sensitive detection systems such as labeled strepta- vidin biotin or EnVision+ (12-17). Many immunohistochemistry laboratories, however, continue to obtain weak cyclin D1 signals despite resorting to the aforesaid strategies. In agreement with this, most mantle cell lymphoma cases included in the present work exhibited weak cyclin D1 positivity 
TABLE 1. Cyclin D1 Immunostaining in Mantle Cell Lymphoma and Control Cases (Follicular Center Cell Lymphoma and Small Lymphocytic Lymphoma) with Three Different Detection Systems

\begin{tabular}{lcccc}
\hline & \multicolumn{2}{c}{ Mantle Cell Lymphoma } & \multirow{2}{*}{ Controls } \\
\cline { 2 - 3 } & Weak & Moderate & Strong & \\
\hline Labelled streptavidin biotin & 17 & 3 & & - \\
EnVision+ & 15 & 5 & & - \\
Catalyzed signal amplification & & & 20 & - \\
\hline
\end{tabular}

when studied with either labeled streptavidin biotin or EnVision+. In contrast, catalyzed signal amplification has proven itself a very effective tool for immunostaining optimization, particularly when the antigen is either poorly represented or heavily masked by undue fixation (18). This catalyzed signal amplification powerful signal enhancement results from the deposition of a biotinylated phenolic compound in the vicinity of the antigen. Using a variety of tissues, Sabattini et al. (13) have explored optimal dilutions for anti-cyclin D1 and other 52 monoclonal antibodies with the aid of six different detection systems including labeled streptavidin biotin, EnVision+, and catalyzed signal amplification. They propose catalyzed signal amplification as the gold standard technique for cyclin D1 immunohistochemistry (13), a recommendation that gains further support from the present work, in which all 20 mantle cell lymphoma cases exhibited maximally intense cyclin D1 immunoreactivity when studied with the catalyzed signal amplification technique.

Recently, Korin et al. (14) have investigated cyclin D1 expression in mantle cell lymphoma using catalyzed signal amplification as a detection system. Unexpectedly, catalyzed signal amplification has failed to show enhanced sensitivity in the hands of these authors, which consequently recommend the concomitant use of several anti-cyclin D1 antibodies to improve detection. The good results obtained in the present work with catalyzed signal amplification are probably related to our use of the autoclave for antigen retrieval, because autoclaving provides optimal time and temperature control and allows primary antibody concentration reductions of $\leq 100$ times. Presumably, the excessive background obtained by Korin et al. (14) with catalyzed signal amplification is caused by their use of different antigen retrieval methods. In our work, antigen retrieval time in the autoclave had to be significantly reduced to prevent an increase in background immunostaining because distortion of protein structure by overheating, in conjunction with high primary antibody concentrations, results in undue nonspecific signal.

Overall, cyclin D1 overexpression is immunohistochemically demonstrable in mantle cell lymphoma with a frequency ranging from $75 \%$ to $100 \%$ according to different authors $(16,19,20)$. Owing to the significant difficulties inherent to cyclin D1 immunohistochemical search, lack of immunoreactivity in some mantle cell lymphoma cases may reasonably be ascribed to the low sensitivity of the methods employed. In such cases, employment of Southern blot, cytogenetics, FISH, or mRNA expression studies allows confirmation of the diagnosis, but they are costly techniques that are not widely available. Much more easily accessible for most pathology laboratories is the catalyzed signal amplification technique, use of which significantly improves the sensitivity of cyclin D1 detection without compromising its specificity. The caveat, however, is that the catalyzed signal amplification method is more laborious and technically demanding than other routinely used detection methods. These problems notwithstanding, catalyzed signal amplification usefulness is availed by the good results obtained by us and other groups even when using automated systems $(13,18)$. In conclusion, we believe that catalyzed signal amplification is an excellent method for immunohistochemical demonstration of cyclin D1 overexpression in mantle cell lymphoma.

\section{REFERENCES}

1. Argatoff LH, Connors JM, Klasa RJ, Horsman DE, Gascoyne RD. Mantle cell lymphoma: a clinicopathologic study of 80 cases. Blood 1997;89:2067-78.

2. Bosch F, Lopez-Guillermo A, Campo E, Ribera JM, Conde E, Piris MA, et al. Mantle cell lymphoma: presenting features, response to therapy, and prognostic factors. Cancer 1998;82: 567-75.

3. Fisher RI, Dahlberg S, Nathwani BN, Banks PM, Miller TP, Grogan TM. A clinical analysis of two indolent lymphoma entities: mantle cell lymphoma and marginal zone lymphoma (including the mucosa-associated lymphoid tissue and monocytoid B-cell subcategories): a Southwest Oncology Group study. Blood 1995;85:1075-82.

4. Norton AJ, Matthews J, Pappa V, Shamash J, Love S, Rohatiner AZ, et al. Mantle cell lymphoma: natural history defined in a serially biopsied population over a 20 -year period. Ann Oncol 1995;6:249-56.

5. Velders GA, Kluin-Nelemans JC, De Boer CJ, Hermans J, Noordijk EM, Schuuring E, et al. Mantle-cell lymphoma: a population-based clinical study. J Clin Oncol 1996;14:126974.

6. The Non-Hodgkin's Lymphoma Classification Project. A clinical evaluation of the international lymphoma study group classification of non-Hodgkin's lymphoma. Blood 1997;89:3909-18.

7. Weisenburger DD, Vose JM, Greiner TC, Lynch JC, Chan WC, Bierman PJ, et al. Mantle cell lymphoma. A clinicopathologic study of 68 cases from the Nebraska Lymphoma Study Group. Am J Hematol 2000;64:190-6.

8. Yang WI, Zukerberg LR, Motokura T, Arnold A, Harris NL. Cyclin D1 (Bcl-1, PRAD1) protein expression in low-grade B-cell lymphomas and reactive hyperplasia. Am J Pathol 1994;145:86-6.

9. de Boer CJ, Schuuring E, Dreef E, Peters G, Bartek J, Kluin $\mathrm{PM}$, et al. Cyclin D1 protein analysis in the diagnosis of mantle cell lymphoma. Blood 1995;86:2715-23. 
10. Zukerberg LR, Yang WI, Arnold A, Harris NL. Cyclin D1 expression in non-Hodgkin's lymphomas. Detection by immunohistochemistry. Am J Clin Pathol 1995;103:756-60.

11. Li JY, Gaillard F, Moreau A, Harousseau JL, Laboisse C, Milpied N, et al. Detection of translocation t(11;14)(q13;q32) in mantle cell lymphoma by fluorescence in situ hybridization. Am J Pathol 1999;154:1449-52.

12. Adams JC. Biotin amplification of biotin and horseradish peroxidase signals in histochemical stains. J Histochem Cytochem 1992;40:1457-63.

13. Sabattini E, Bisgaard K, Ascani S, Poggi S, Piccioli M, Ceccarelli $\mathrm{C}$, et al. The EnVision+ system: a new immunohistochemical method for diagnostics and research. Critical comparison with the APAAP, ChemMate, CSA, LABC, and SABC techniques. J Clin Pathol 1998;51:506-11.

14. Korin HW, Schwartz MR, Chirala M, Younes M. Optimized cyclin D1 immunoperoxidase staining in mantle cell lymphoma. Appl Immunohistochem Mol Morphol 2000;8:5760.

15. Chan JKC. Reliable immunostaining of cyclin D1 is difficult, but the problems can be overcome. Histopathology 1999;34:266-8.
16. Miranda RN, Briggs RC, Kinney MC, Veno PA, Hammer RD, Cousar JB. Immunohistochemical detection of cyclin D1 using optimized conditions is highly specific for mantle cell lymphoma and hairy cell leukemia. Mod Pathol 2000;13: 1308-14.

17. Miller KD, Munson P, Isaacson. Optimizing cyclin D1 immunostaining of mantle cell lymphoma. Histopathology 1999;34:268-70.

18. Hashizume K, Hatanaka Y, Kamihara Y, Tani Y. Automated immunohistochemical staining of formalin-fixed and paraffin-embedded tissues using a catalyzed signal amplification method. Appl Immunohistochem Mol Morphol 2001; 9:54-60.

19. Ott MM, Helbing A, Ott G, Bartek J, Fischer L, Durr A, et al. bcl-1 rearrangement and cyclin D1 protein expression in mantle cell lymphoma. J Pathol 1996;179:238-42.

20. Aguilera NS, Bijwaard KE, Duncan B, Krafft AE, Chu WS, Abbondanzo SL, et al. Differential expression of cyclin D1 in mantle cell lymphoma and other non-Hodgkin's lymphomas. Am J Pathol 1998;153:1969-76.

\section{Book Review}

\section{Silverberg S: Atlas of Breast Pathology, 255 pp, Philadelphia, W. B. Saunders, 2002 (\$179.00).}

This book makes a good argument in favor of single authorship for atlases. The Atlas of Breast Pathology takes the form usually reserved for textbooks in which a different individual authors each chapter. The result is an uneven effort in which some of the chapters provide a coherent summary of the topic (such as the chapter on infiltrating duct carcinoma, not otherwise specified), while others display a compendium of sub-optimal photographs (such as the chapter on normal anatomy and physiologic changes). That being said, the atlas does appear to include the full range of breast pathology, including inflammatory, benign, and malignant histology. Notable features include a chapter on radiologic techniques and core needle biopsy that effectively juxtaposes mammographic and histologic findings, an interesting chapter on iatrogenic lesions of the breast such as those caused by prostheses, and an expertly annotated chapter authored by Dr. Silverberg himself on infiltrating carcinomas other than infiltrating duct carcinomas not otherwise specified. The most outstanding portion of the atlas is the superb chapter on fine needle aspiration cytology authored by Dr. Shahla Masood, who organizes the chapter such that several related entities are presented on a single page for convenient comparison. She also presents the features of the most common diagnoses in list form for easy reference. Overall, The Atlas of Breast Pathology serves as a useful supplement to more general textbooks on the pathologist's reference shelf.

\author{
Brian E. Moore \\ Roger Williams Medical Center \\ Providence, Rhode Island
}

